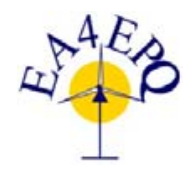

International Conference on Renewable Energies and Power Quality (ICREPQ'13) Bilbao (Spain), $20^{\text {th }}$ to $22^{\text {th }}$ March, 2013

Renewable Energy and Power Quality. Fournal (RE\&PQJ)

ISSN 2172-038 X, No.11, March 2013

\title{
Detection of Induction Motors Rotor/Stator Faults Using Electrical Signatures Analysis
}

\author{
Somaya A. M. Shehata, Hamdy S. El-Goharey, Mostafa I. Marei, Ahmed K. Ibrahim \\ Department of Electrical Power and Machines Engineering, Ain-Shams University, Cairo, Egypt \\ e-mail: somayaafify@hotmail.com, hamdyk@hotmail.com,mostafamarei@yahoo.ca, ahkhibess@yahoo.com
}

\begin{abstract}
In this work induction motor faults detection using electrical signature analysis techniques are introduced, and the advantages and disadvantages of these techniques are explained. Stator phase current signature, stator current locus diagram, stator current vector signature, partial power signature, and total power signature are selected for the simulation study applied for $4 \mathrm{Kw}$ squirrel cage induction motor. Simulation results are shown to explain how these signatures can be used to detect rotor/stator faults. And finally the performance of each technique based on the sensitivity to fault severity, the effect of motor loading, and cost required for the practical implementation is discussed.
\end{abstract}

\section{Key words}

Induction motor, motor electrical signature analysis, rotor fault detection, stator fault detection.

\section{Introduction}

Induction machines are the backbones of many industrial processes due to its robustness and reliability. Online fault diagnostics of these machines are very important to ensure safe operation, timely maintenance, increased operation reliability, and preventive rescue especially in high power applications. Failures in induction motors can be classified into four main groups or modes [1]-[4]:

- Bearings and rotor eccentricity faults;

- Stator winding faults;

- Rotor winding faults (i.e. rotor bars and end-rings in the case of squirrel cage motors);

- Faults in external devices which regroup the accessories of the drive system.

Researches reveal that motor currents and/or voltages signals are always modulated by fault condition inside the motor [5]. Using different signal processing and mathematics techniques, these signals can be analyzed and faults inside the motor can be identified. The main advantages of using electrical signals instead of any other types of signals (e.g. vibration, acoustic,...etc) are:

- Electrical signals are easier, simpler, and cheaper to be measured and stored.

- Direct access to motor itself is not required and signals can be measured from control panels supplying the motor, thus immersed motors or motors in hazardous areas can be monitored.

- Online fault monitoring can be achieved without the need to shutdown the motor.

- Faults can be identified at an early stage before becoming severe. Hence, sudden motor shut down are avoided, and maintenance cost is reduced.

\section{Motor electrical signature Analysis (MESA)}

Currents and/or voltages signals can be selected to be analyzed to detect faults inside the motor. The selected signal is called a diagnosis media, and the output of the analysis applied to the selected diagnosis media is called a signature. Each healthy motor gives a certain signature and this signature is affected when faults exist inside the motor. By comparing signatures during motor operation with its original healthy signature, faults can be identified at early occurrence stage. Hence decisions can be taken whether to continue or to stop the motor operation and start the maintenance before developing into a more severe case. The following electrical signals are selected and are used as signatures to detect different rotor and stator faults.

\section{A. Fault Detection Using Stator Phase Current Signature}

Stator phase current is measured directly using current transformer (CT) or current transducer, and then unwanted high frequencies and noise components are filtered. A window of sampled points is recorded for a certain time depending on frequency resolution selected. The Fast Fourier transform (FFT) algorithm is then applied to obtain the stator current spectrum or the signature. For a healthy motor this signature contains the fundamental supply frequency component and other components are neglected. When a fault exists inside the motor some of frequency components magnitudes are increased with respect to the fundamental component depending on fault type and severity. Thus, by identifying frequencies and magnitudes of these components with respect to fundamental component, both fault type and severity can be addressed $[6,7]$. This technique is simple and requires 
only the measurement of one phase current. This reduces the cost of hardware and memory size required.

\section{B. Fault Detection Using Stator Current Locus Signature}

In this technique the direct component $I_{d}$ and the quadrature component $I_{q}$ of the stator current vector are used to represent the current locus of the stator current. Where $I_{d}$ and $I_{q}$ are calculated using park's technique taking the stator as a reference frame as follows:

$$
\begin{aligned}
& I_{d}=\sqrt{\frac{2}{3}} I_{A}-\sqrt{\frac{1}{6}} I_{B}-\sqrt{\frac{1}{6}} I_{C} \\
& I_{q}=\sqrt{\frac{1}{2}} I_{B}-\sqrt{\frac{1}{2}} I_{C}
\end{aligned}
$$

where $I_{A}, I_{B}$, and $I_{C}$ are the stator three phase currents. For a healthy motor, the current locus draws a circle centered at the origin. The existence of faults inside the motor causes deviations of the locus from the healthy locus. These deviations are then used to identify fault type and severity [9]. The advantage of this method is that it does not require the application of the FFT algorithm or frequency analyzers, but it requires the measurements of the three phase currents.

\section{Fault Detection Using Park's Stator Current Vector Signature}

More rich information can be obtained if the three phase currents are utilized together by using Park's stator current vector $I_{s}$ as a signature instead of using one phase current only. Park's current vector can be calculated as:

$$
I_{s}=I_{d}+j I_{q}
$$

The modulus of $I_{s}$ is then calculated and the FFT algorithm is applied to get the Park's stator current vector signature. This signature is compared with the healthy signature to identify faults types and severities. This method gives more rich information but requires more complicated hardware and larger size of memory [8].

\section{Fault Detection Using Partial Power Signature}

It is found that the use of partial power signatures gives more information about faults than the use of stator current signatures [6]. This can be achieved by applying the FFT algorithm on the instantaneous partial power signals. The instantaneous partial power for the three phase motors can be defined as:

$$
\begin{aligned}
& P_{A B}=V_{A B}{ }^{*} I_{A} \\
& P_{C B}=V_{C B}{ }^{*} I_{C}
\end{aligned}
$$

where, $P_{A B}$ and $P_{C B}$ are the partial power signals, $V_{A B}$ is line to line voltage between phase $\mathrm{A}$ and phase $\mathrm{B}$, and $V_{C B}$ is the line to line voltage between phase $\mathrm{C}$ and phase $\mathrm{B}$.

For Healthy motors, the partial power spectrum contains a dc component and another component oscillating at twice the supply frequency. When faults exist, the currents are modulated by fault frequency components. Hence, the partial power spectrum will contain additional components which express faults types. The magnitude of these components with respect to the DC component (or twice the supply frequency component) will express faults severity. This method requires the measurements of motor currents and voltages.

\section{E. Fault Detection Using Total Power Signature}

In this technique, the total power signal is used instead of the partial power signals where:

$$
P_{A B C}=P_{A B}+P_{C B}
$$

The signature of $\mathrm{P}_{\mathrm{ABC}}$ contains only a DC component for a healthy motor expressing the total power. For a motor under faults, the signature of $\mathrm{P}_{\mathrm{ABC}}$ contains other components expressing fault type and severity [6].

\section{Signature Analysis}

Simulation results are obtained for an induction motor, with 28 squirrel cage rotor bars, under different loading

\begin{tabular}{|c|c|c|}
\hline Symbol & Description & Magnitude \\
\hline$V_{s}$ & $\begin{array}{l}\text { Input Supply Phase } \\
\text { Voltage }\end{array}$ & 220 Volts \\
\hline$f_{s}$ & $\begin{array}{l}\text { Input Supply } \\
\text { Frequency }\end{array}$ & 50 Hertz \\
\hline$N_{s}$ & $\begin{array}{l}\text { Effective Number of } \\
\text { Stator winding turns }\end{array}$ & 156 turns \\
\hline$R_{s}$ & $\begin{array}{l}\text { Stator windings Ohmic } \\
\text { resistance }\end{array}$ & $1.5 \Omega$ \\
\hline$L_{l s}$ & $\begin{array}{l}\text { Stator windings } \\
\text { Leakage inductance }\end{array}$ & $7 \mathrm{mH}$ \\
\hline$p$ & Number of pole pairs & 1 \\
\hline$n$ & Number of rotor bars & 28 \\
\hline$R_{b}$ & Rotor bar resistance & $96.940036 \mu \Omega$ \\
\hline$R_{s}$ & $\begin{array}{l}\text { End ring segment } \\
\text { resistance }\end{array}$ & $5 \mu \Omega$ \\
\hline$L_{b}$ & $\begin{array}{l}\text { Rotor bar self } \\
\text { inductance }\end{array}$ & $0.28 \mu \mathrm{H}$ \\
\hline$L_{e}$ & $\begin{array}{l}\text { End ring segment self } \\
\text { inductance }\end{array}$ & $0.036 \mu \mathrm{H}$ \\
\hline$r$ & Air gap average radius & $70 \mathrm{~mm}$ \\
\hline$g$ & Air gap length & $0.28 \mathrm{~mm}$ \\
\hline$L$ & Rotor effective length & $120 \mathrm{~mm}$ \\
\hline
\end{tabular}
conditions. The motor is rated at $380 \mathrm{~V}, 50 \mathrm{~Hz}$, and $4 \mathrm{KW}$. The induction motor model is based on winding function theory [10], and its parameters are given in Table 1 .

TABLE I

INDUCTION MOTOR PARAMETERS

\section{A. Healthy Motor Signature Analysis}

The healthy induction motor is simulated under $100 \%$ full load. The steady state currents and voltages from the simulation are used to obtained the signatures explained in the previous section.

Figure 1 shows the stator phase A current signature for a healthy motor. It is clear that only the fundamental supply frequency $(50 \mathrm{~Hz})$ component exists. In Fig. 2, Park's current vector components $\left(\mathrm{I}_{\mathrm{d}}\right.$ and $\left.\mathrm{I}_{\mathrm{q}}\right)$ are used to draw the stator current locus. The locus draws a circle centered at the origin for the healthy induction motor. Figure 3 shows 
the healthy motor vector current spectrum. Only the DC component exists and all other components are neglected. Figure 4 shows the partial power signature using the calculated instantaneous partial power $\left(\mathrm{P}_{\mathrm{ab}}\right)$. Partial power signature contains two components; one at DC frequency and the other oscillating at twice the supply frequency. Figure 5 shows the total power signature for the healthy induction motor. It is noticed that there is some kind of similarity between total power and stator current vector signature. This is due to the assumption of the pure sinusoidal voltage supply. This is only true for the healthy case as will be shown later.

\section{B. Rotor Fault Signature Analysis}

The motor is assumed operating at full load with three broken bars in the rotor cage. This fault is simulated by increasing the internal resistances of the broken bars so that currents pass through these bars are neglected [10]. Figure 6 presents the stator phase current signature. Multiple of peaks or sidebands components appear around the fundamental component at frequencies of $f_{s}(1 \pm 2 m s)$, where $m=1,2, \ldots$ and $s=$ motor slip $[2,3,7,8]$. Figure 7 demonstrates that the effect of rotor fault is to increase the thickness of the stator current locus as compared to Fig.2. In Figs. 8-10 multiple peaks at frequencies of $2 m s f_{s}$ appear due to the faulty rotor. These peaks are called the characteristic components as they express the characteristics of the fault not the motor itself $[2,3]$.

\section{Stator fault Signature Analysis}

The main advantage of MESA is to detect faults at an early stage. Most of stator faults start with inter-turn short circuits and then develop into open or short circuits depending on motor operation. As previously mentioned, the motor is simulated at $100 \%$ full load with an inter-turn short circuit ( $20 \%$ of phase A turns). Figure 11 shows that the third harmonic component $(150 \mathrm{~Hz})$ appears in phase $\mathrm{A}$ current signature due to inter-turn fault in this phase. In Fig.12, the stator current locus is an ellipse instead of a circle. This is because, under inter-turn short circuit, the stator winding is unbalanced and draws unbalanced three phase currents. Figure 13 shows that the stator current vector signature has multiple peaks at frequencies of $2 \mathrm{mf}$. It is worth to mention that, for the this fault, the number of detected peaks in the current vector signature is higher than that of the phase current signature. This is because more rich information is obtained due to the use of the three phase currents and not only a single phase current. When using the partial power signature, Fig. 14 shows a peak at a frequency higher than twice the supply frequency due to the stator fault. The total power signature shows peaks at $2 \mathrm{mf}_{\mathrm{s}}$ for stator fault as indicated in Fig. 15. For stator faults it is enough to detect peaks at higher than the twice of the supply frequency.

\section{Signature Performance}

The performance of the signature is tested for different rotor and stator fault severities ( 1 to 7 broken rotor bars, and $5 \%, 10 \%, 15 \%$ and $20 \%$ inter-turn stator short circuit) under different loading levels.
When the stator phase current signature is used, Fig.16 displays the ratio of the first left sideband peak, $f=f_{s}(1-2 s)$, to the fundamental component in decibel $(\mathrm{dB})$ for different rotor fault severities and different loading levels. It is noted that, for the same loading level, the magnitude increases as fault severity increases. In some cases the magnitude of the first peak remains unchanged while the fault severity increases. This problem can be solved by monitoring more than one peak at the same time. At light loads, peaks may not exist and the method fails to detect rotor faults especially for low severity faults. This signature is also used to detect stator faults by monitoring the $3^{\text {rd }}$ harmonic component $(150 \mathrm{~Hz})$. The ratio, in $\mathrm{dB}$, of the $3^{\text {rd }}$ harmonic magnitude to the fundamental slightly increases with the severity of the faults, Fig. 17.

In Fig. 18, the stator current locus is used to detect rotor faults by measuring the thickness of the locus in $\mathrm{dB}$. It can be noted that the thickness increases as severity of the fault or the loading level increases. The stator current locus is also used to detect stator faults by calculating the ratio between the largest and the smallest diameters of the ellipse in dB. Fig. 19 shows that the ratio increases with the severity for the same loading level. Also, it increases and then decreases as the loading level increases for the same severity level.

The Park's current vector signature is used to detect rotor and stator faults. This is done by monitoring the peaks at frequencies $2 s f_{s}$ and $100 \mathrm{~Hz}$ for rotor and stator faults respectively. Figs. 20 and 21 show that the peak to DC component ratios (in $\mathrm{dB}$ ) increase as fault severity increases. For rotor faults this ratio is slightly affected by the load level, while for stator faults it increases as loading level decreases for the same degree of severity.

Figures 22 - 25 display the effects of fault severity and load level on the detection of rotor and stator faults using partial and total power signatures. For rotor faults the peak of the frequency component $2 s f_{s}$ (between the DC and twice the supply frequency) is monitored. Figs. 22 and 24 show that the ratio of this peak to the DC component (in $\mathrm{dB}$ ) linearly increases as the severity of rotor faults increases. The effect of varying the load level is more pronounced with the total power signature than with the partial power signature.

Peaks of the first components at frequencies higher than twice the supply frequency are usually detected for the diagnosis of stator faults. Figs. 23 and 25 display the ratio of the first peaks (at $200 \mathrm{~Hz}$ for partial power signature, and at $100 \mathrm{~Hz}$ for total power signature) to the DC components in $\mathrm{dB}$. The figures reveal a pronounced variation in this ratio when using the total power signature more than with the partial power signature. Hence, the total power signature can diagnose stator faults better than the partial power signature.

\section{Conclusion}

In this paper, different electric signatures are used to detect rotor and stator faults of induction motors. Based on the results of the paper, it is found that: 


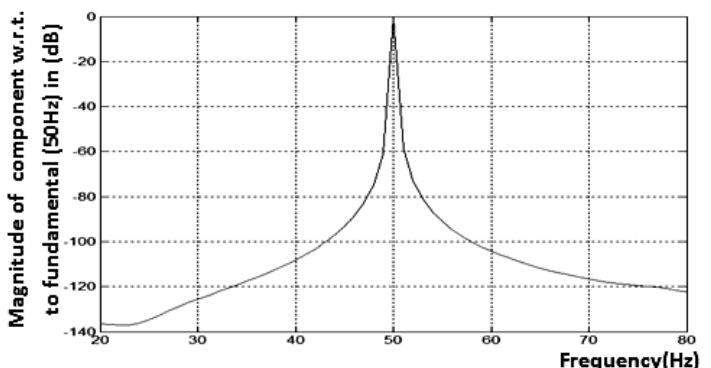

Fig. 1 Stator phase current signature for a healthy induction motor $\left(\mathrm{I}_{\mathrm{a}}\right)$.

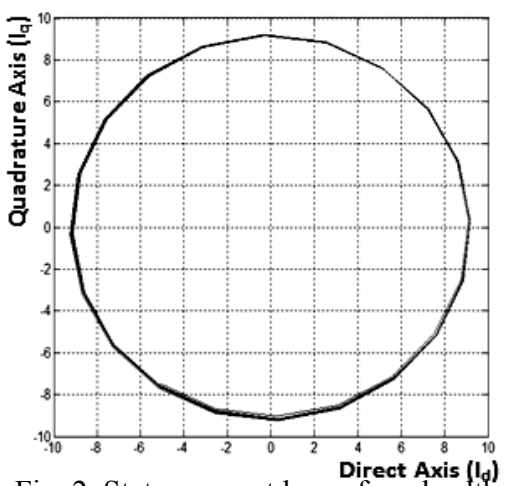

Fig. 2 Stator current locus for a healthy induction motor.

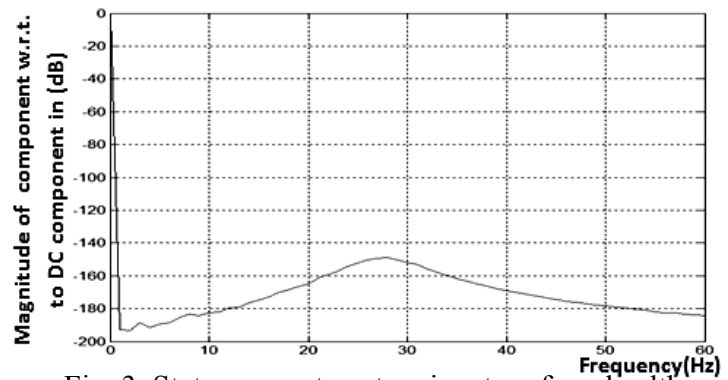

Fig. 3 Stator current vector signature for a healthy induction motor.

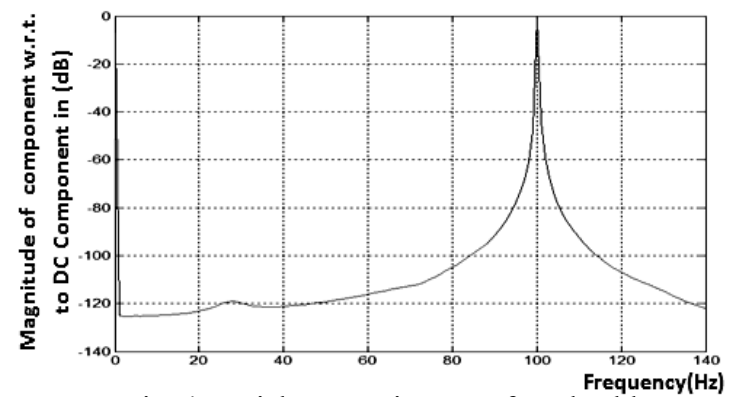

Fig. 4 Partial power signature for a healthy induction motor $\left(\mathrm{P}_{\mathrm{ab}}\right)$.

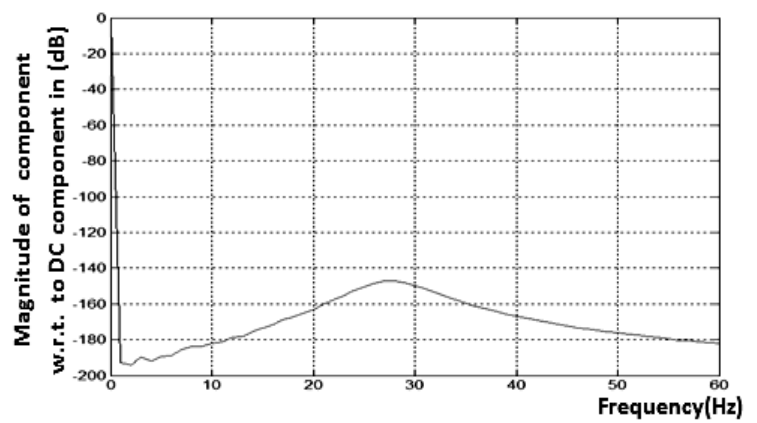

Fig. 5 Total power signature for a healthy induction motor.

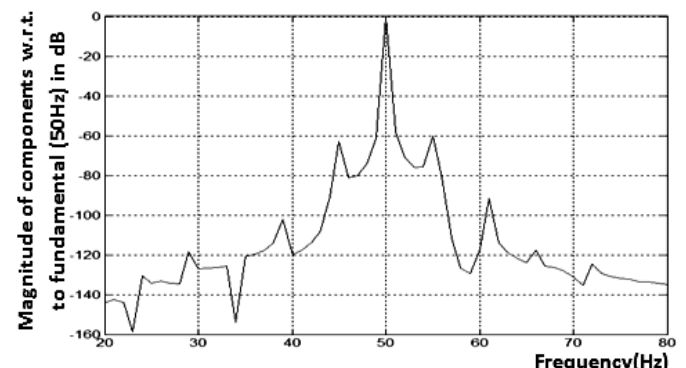

Fig. 6 Stator phase current signature for a motor with three broken rotor bars $\left(\mathrm{I}_{2}\right)$.

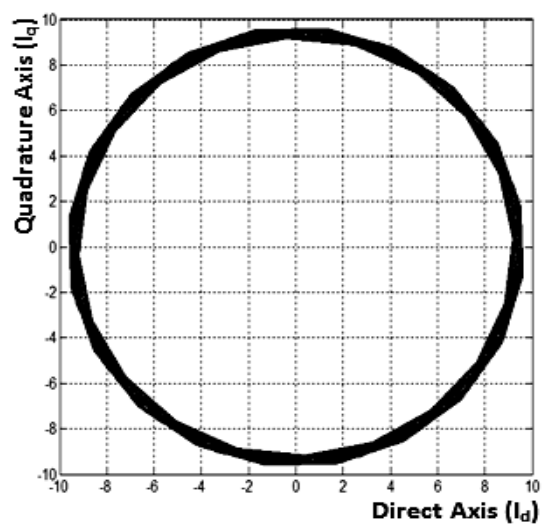

Fig. 7 Stator current locus for a motor with three broken rotor bars.

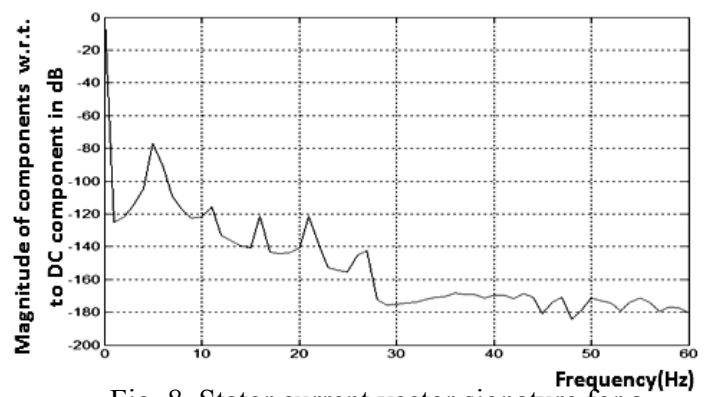

Fig. 8 Stator current vector signature for a motor with three broken rotor bars.

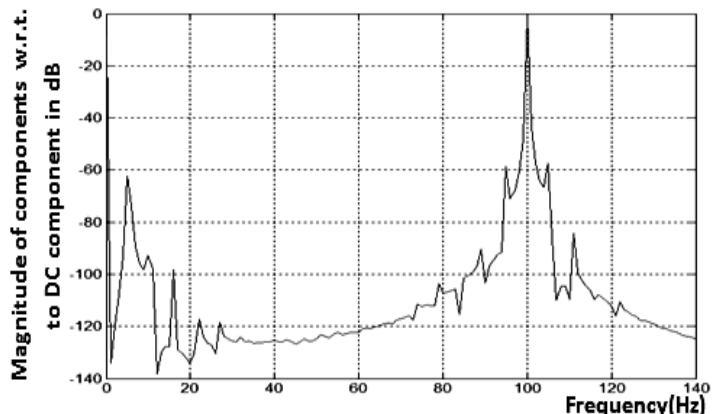

Fig. 9 Partial power signature for a motor with three broken rotor bars $\left(\mathrm{P}_{\mathrm{ab}}\right)$.

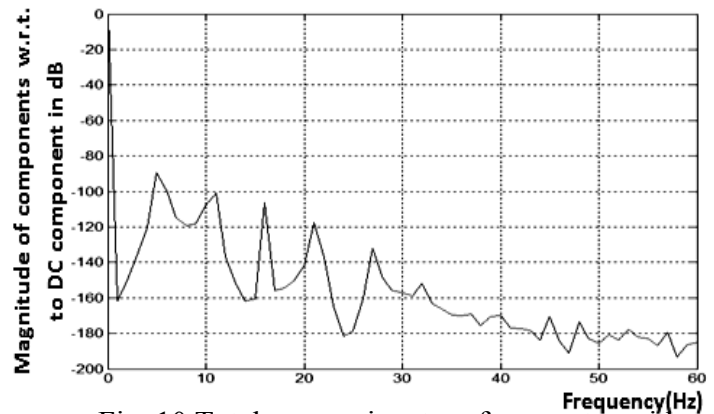

Fig. 10 Total power signature for a motor with three broken rotor bars. 


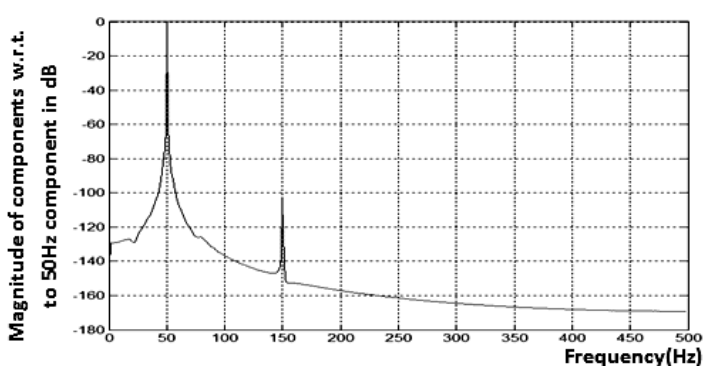

Fig. 11 Stator phase current signature $\left(\mathrm{I}_{\mathrm{a}}\right)$ for a motor with $20 \%$ of inter-turn short circuit in phase A.

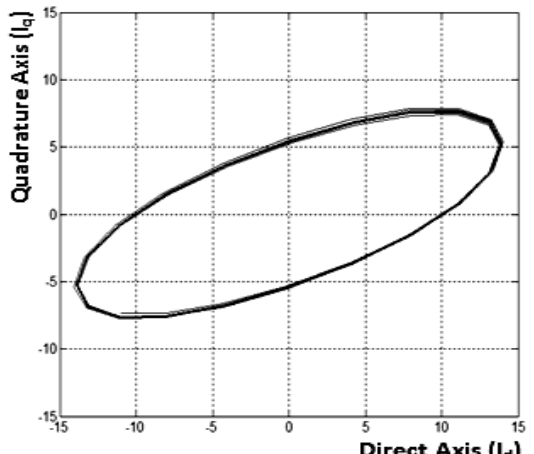

Fig.12 Stator current locus for a motor with $20 \%$ of inter-turn short circuit on phase A.

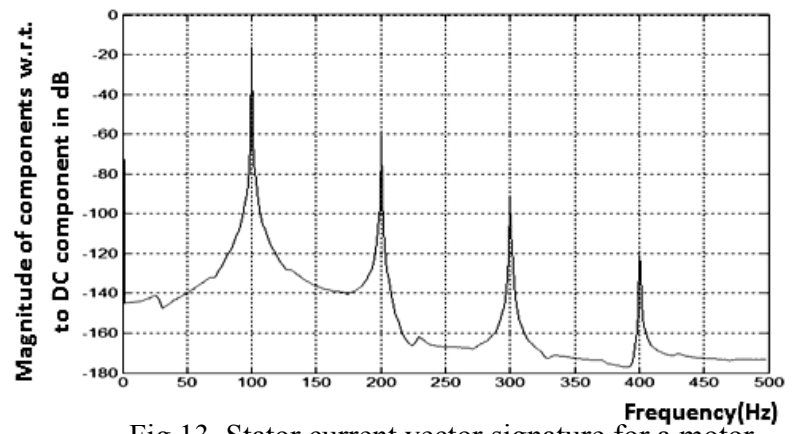

Fig.13 Stator current vector signature for a motor with $20 \%$ of inter-turn short circuit in phase A.

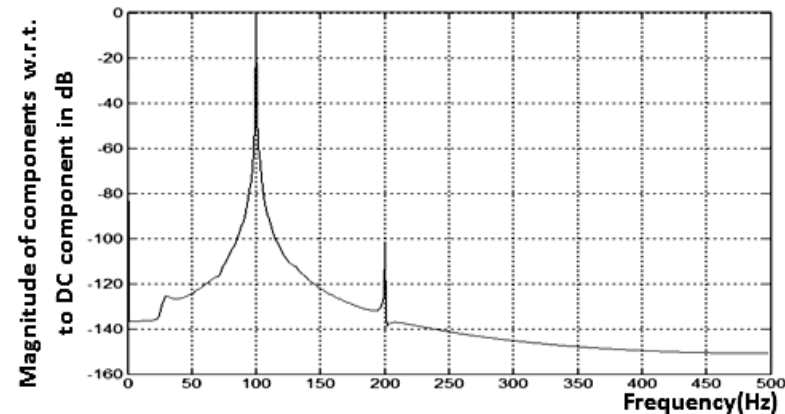

Fig.14 Partial power signature $\left(\mathrm{P}_{\mathrm{ab}}\right)$ for a motor with $20 \%$ of inter-turn short circuit in phase A.

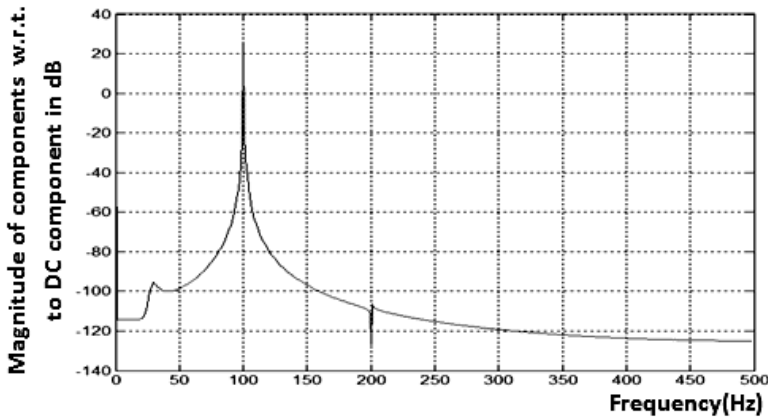

Fig. 15 Total power signature for a motor with $20 \%$ of inter-turn short circuit in phase A.

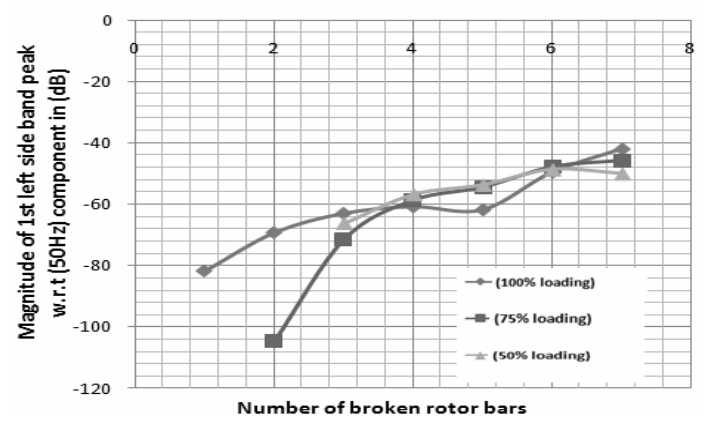

Fig. 16 Effect of rotor fault severity and motor loading on rotor fault detection using stator phase current signature.

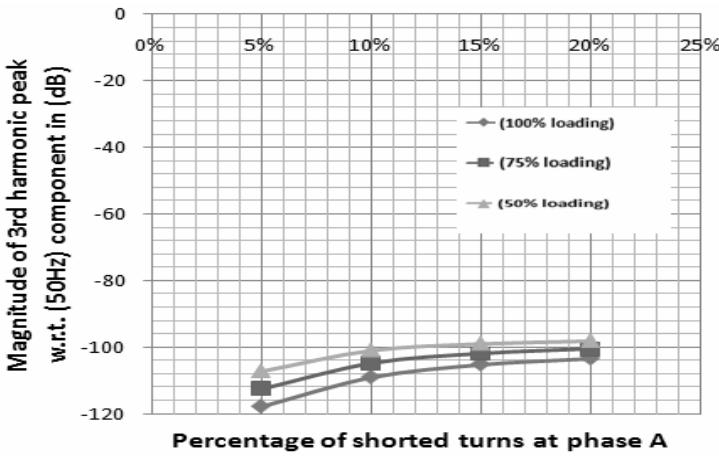

Fig. 17 Effect of stator fault severity and motor loading on stator fault detection using phase current signature.

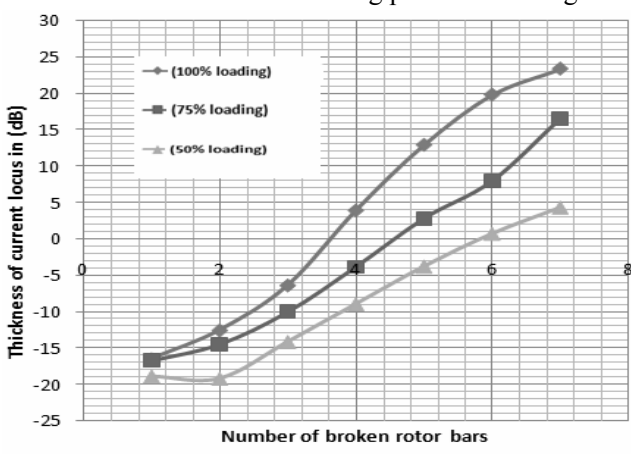

Fig. 18 Effect of rotor fault severity and motor loading on rotor fault detection using stator current locus.

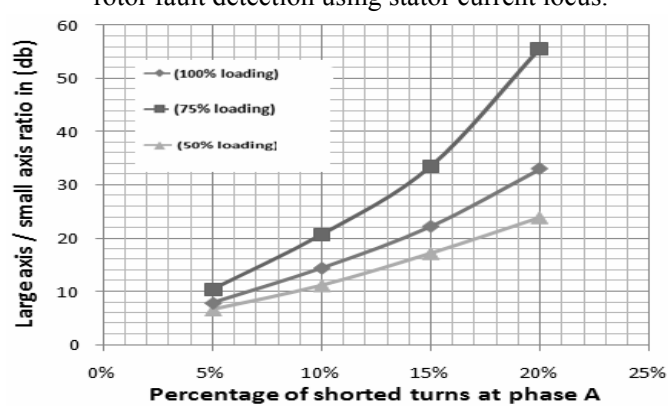

Fig. 19 Effect of stator fault severity and motor loading on stator fault detection using stator current locus.

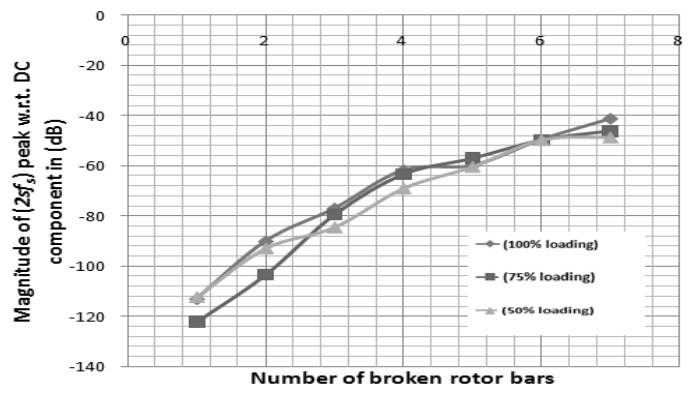

Fig. 20 Effect of rotor fault severity and motor loading on rotor fault detection using stator current vector signature. 


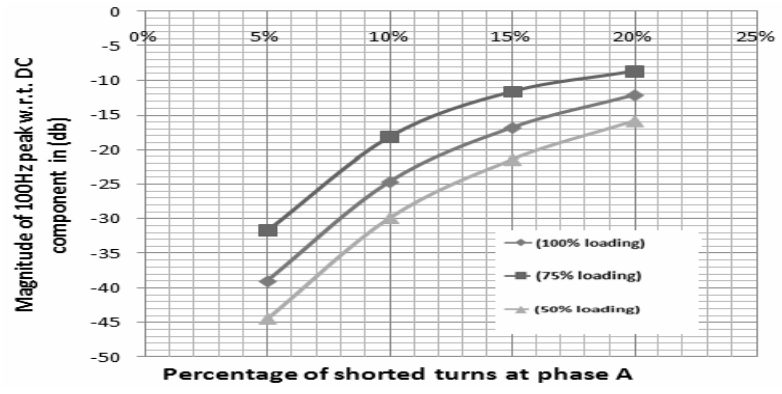

Fig. 21 The effect of stator fault severity and motor loading on stator fault detection using stator current vector signature.

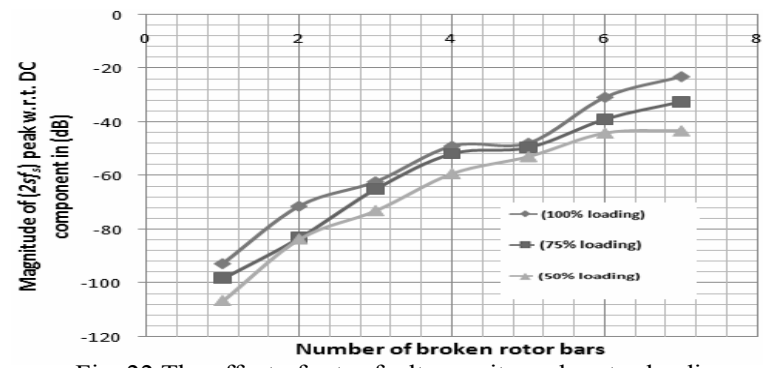

Fig. 22 The effect of rotor fault severity and motor loading on rotor fault detection using partial power signature.

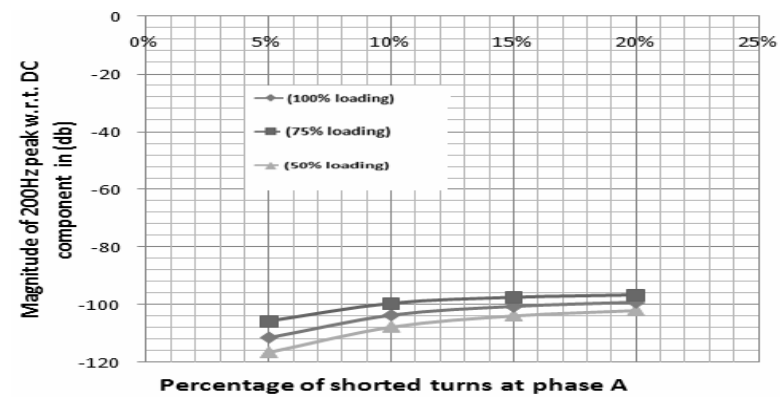

Fig. 23 the effect of stator fault severity and motor loading on stator fault detection using partial power signature.

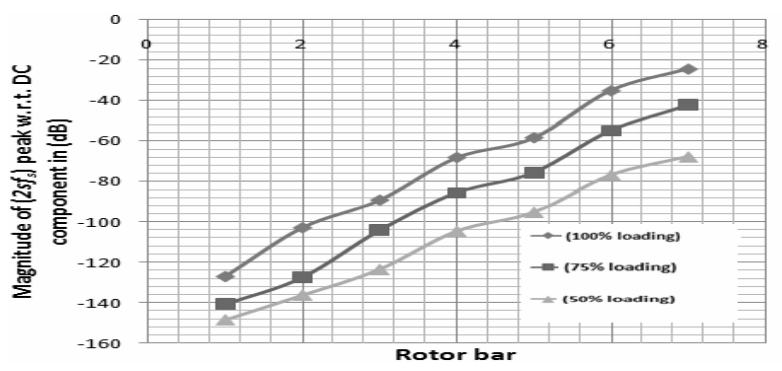

Fig. 24 the effect of rotor fault severity and motor loading on rotor fault detection using total power signature.

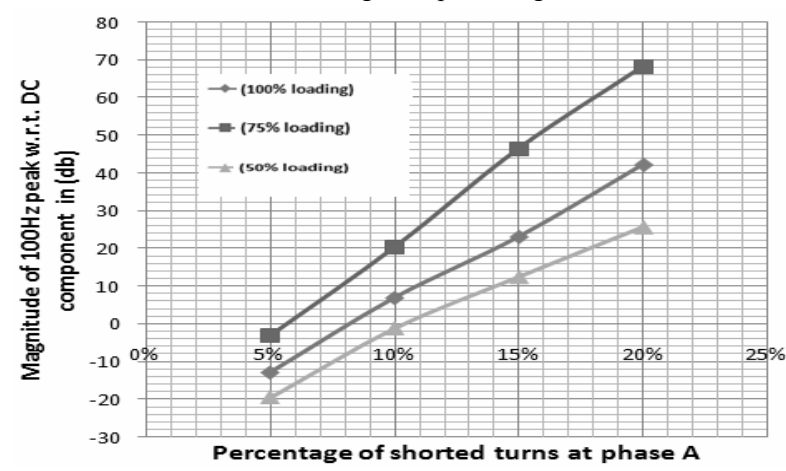

Fig.25. the effect of stator fault severity and motor loading on stator fault detection using total power signature.
(1) Fault detection using the stator phase current signature is the simplest and cheapest technique. However, it is significantly affected by motor loading (some rotor faults may not be detected at light loads). Hence, it is recommended to monitor more than one peak to improve the sensitivity of detection for some fault cases. Also detection of stator faults is quite difficult because of the narrow range of change of the detected peaks.

(2) The detection of faults using park's current locus or vector seems to be perfect for both rotor and stator faults and less affected by motor loading. However, it requires the simultaneous measurement of the three phase currents.

(3) Partial power signature is perfect for rotor faults signature, while total power signature is excellent for both stator and rotor faults detection and gives a nearly linear response with fault severity. The main disadvantage of using power signatures (partial or total) is the need to measure both current and voltage signals of the motor.

(4) For all signatures, it is recommended to detect rotor faults at high motor load levels, while it is better to detect stator faults at light load levels.

\section{References}

[1] M.L. Sin, W.L. Soong and N. Ertugrul "Induction Machine On-Line Condition Monitoring And Fault Diagnosis - A Survey", University of Adelaide.

[2] J. Sprooten,"Finite Element and Electrical Circuit Modeling of Faulty Induction Machines Study of Internal Effects and Fault Detection Techniques", Dept of Bio, Electro And Mechanical Systems, Universit $\mid e$ Libre de Bruxelles.

[3] M. D. Negrea, "Electromagnetic flux monitoring for detecting faults in electrical machines," Ph.D. Thesis, Helsinki University of Technology, Finland, 2006.

[4] Ondřej Vítek, "Induction Machine Diagnosis Using Stator Current and Magnetic Field Analysis", Zeszyty Problemowe - Maszyny Elektryczne Nr 82/2009.

[5] A. Korde,"On-Line Condition Monitoring of Motor Using Electrical Signature Analysis", presented at the "Recent Advances in Condition-Based Plant Maintenance" A seminar organized by the Indian Institute of Plant Engineers, Mumbai, 2002.

[6] A. M. Trzynadlowski, and E. Ritchie, "Comparative Investigation of Diagnostic Media for Induction Motors: A Case of Rotor Cage Faults," IEEE Trans. on industrial electronics, Vol. 47, No. 5, Oct. 2000, pp. 1092- 1099.

[7] Neelam Mehala, Ratna Dahiya, "An Approach of Condition Monitoring of Induction Motor Using MCSA",International journal of systems applications, Engineering and development, Volume 1, Issue 1, 2007.

[8] M.E. Benbouzid, "A Review of Induction Motors Signature Analysis as a Medium for Faults Detection", IEEE trans. Ind. Electronics, Vol. 47, No. 5, Oct 2000, pp. 984-993.

[9] A. J. M. Cardoso, S. M. A. Cruz, D. S. B. Fonseca "InterTurn Stator Winding Fault Diagnosis in 3-phase Induction Motors,by Park's Vector Approach," IEEE Trans. on Energy Conversion, Vol.14, No. 3, Sept 1999, pp.595-598.

[10] A.K. Ibrahim, M.I. Marei, H.S. El-Goharey, S.A.M. Shehata, "Modeling of Induction Motor Based on Winding Function Theory to Study Motor under Stator/Rotor Internal Faults," $14^{\text {th }}$ Int. Middle East Power Systems Conference, (MEPCON'10), Cairo, Egypt, December 19-21, 2010. 